\title{
Estresse ocupacional na enfermagem atuante na unidade de terapia intensiva'
}

\author{
Larissa Borges Teixeira² \\ Lorena Uchôa Portela Veloso 3 \\ Ítalo Arão Pereira Ribeiro 4 \\ Tauane Nunes de Oliveira ${ }^{5}$ \\ Antônio Carlos Leal Cortez ${ }^{6}$
}

doi:10.11144/Javeriana.ie19-2.eoea

Como citar: Teixeira L, Veloso L, Ribeiro IA, Oliveira T, Cortez AC. Estresse ocupacional na enfermagem atuante na unidade de terapia intensiva: uma revisão da literatura. Investig Enferm Imagen Desarr. 2017;19(2):195-211. http://dx.doi.org/10.11144/ Javeriana.ie19-2.eoea

1. Artigo original de pesquisa. Data de recebido: 13 de outubro de 2014. Data de aceitação: 12 de agosto de 2016.

2. Enfermeira. Especialista em Unidade de Terapia Intensiva pela Universidade Estadual do Piauí (UESPI), Brasil. Teresina-PI. Correio eletrônico: borges.miss@hotmail.com

3. Mestre em Enfermagem pela Universidade Federal do Piauí (UFPI), Brasil. Docente do curso de graduação em Enfermagem da Universidade Estadual do Piauí (UESPI). Enfermeira da Fundação Municipal de Saúde (FMS). Teresina-PI. Correio eletrônico: lorenaupveloso@gmail.com

4. Enfermeiro. Especialista em Docência do Ensino Superior pela Faculdade Evangélica do Meio Norte (FAEME), Brasil. Teresina-PI. Correio eletrônico: italoaarao@hotmail.com

5. Enfermeira, Especialista da Unidade de Terapia Intensiva pelo Centro Universitario (Uninovafapi). Teresina-PI, Brasil. Especialista em Gestão em Saúde Publica pelo Instituto de Ensino Superior Franciscano (IESF), Brasil. Paço do Lumiar-MA. Enfermeira na Unidade de Terapia Intensiva do Hospital Regional Tibério Nunes, Brasil. Floriano-PI. Correio eletrônico: tauanenunes@hotmail.com

6. Profissional de Educação Física, Universidade Estadual do Piauí (UESPI), Brasil. Especialista em Gestão da Atividade Física Nutrição e Saúde, com Habilitação em Docência do Ensino Superior-FAR, Mestre em Alimentos e Nutrição, Universidade Federal do Piauí (UFPI). Pesquisador do Laboratório de Biociências do Movimento Humano, Universidade Federal do Rio de Janeiro. Professor e coordenador dos Cursos de Bacharelado e Licenciatura em Educação Física, Faculdade Santo Agostinho. 


\section{Resumo}

Introdução: O estresse tem sido um dos problemas que mais tem acometido a equipe de enfermagem dentro da unidade de terapia intensiva (UTI), causando prejuízo funcional, bem como instabilidade na saúde desses profissionais. Objetivo: Descrever, através da revisão integrativa, o estresse no trabalho da enfermagem na UTI, bem como identificar fatores, sinais e sintomas associados ao estresse ocupacional. Método: Trata-se de uma pesquisa integrativa, utilizando como banco de dados a Biblioteca Virtual de Saúde (BVS), publicados entre 2002 à 2012. Resultados: As informações analisadas permitiram a caracterização das principais evidências em três categorias: 1) prevalência do estresse vivenciado pela enfermagem na UTI; 2) fatores causadores de estresse na UTI e suas consequências para enfermagem; e 3) principais sinais e sintomas de estresse na enfermagem no ambiente da UTI. Os resultados demonstraram a magnitude e os principais agravamentos dessa perturbação para os profissionais. Conclusão: O estresse ocupacional pode afetar todo e qualquer trabalhador, uma vez que todo trabalho é passivel de particularidades especificas que podem provocar situações geradoras de estresse. É necessário a identificação de medidas e técnicas que minimizem os efeitos do estresse para a enfermagem que atua na UTI com a finalidade de garantir o bem-estar desses profissionais para desempenharem com inteira qualidade suas funções.

Palabras-chave: estresse ocupacional; enfermagem; unidade de terapia intensiva

\section{Occupational Stress in Nursing Active in Intensive Care Unit}

\section{Abstract}

Introduction: Stress has been one of the problems that has most affected the nursing staff in the ICU, causing functional impairment, as well as instability in the health of these professionals. Objective: To describe, through the integrative review, the stress in nursing work in Intensive Care Unit (ICU) and to identify factors, signs and symptoms associated with occupational stress. Method: This is an integrative research, using as database Virtual Health Library (VHL), published from 2002 to 2012. Results: The information analyzed allowed the characterization of the main evidence in three categories: 1) Prevalence of experienced stress by Nursing in ICUs; 2) factors causing stress in the ICU and its consequences for nursing; and 3) Key signs and symptoms of stress in nursing in the ICU environment. The results demonstrated the magnitude and the main aggravations of this disturbance to the professionals. Conclusion: Occupational stress can affect each and every worker, since all work is subject to specific features which may cause situations that cause stress. the identification of measures and techniques is necessary to minimize the effects of stress for nursing engaged in the ICU in order to ensure the welfare of these professionals to perform with full quality their duties.

Keywords: Occupational stress; nursing; intensive care unit 


\section{Estrés laboral en enfermería activa en la unidad de cuidado intensivo}

\section{Resumen}

Introducción: El estrés es uno de los problemas que más afecta al personal de enfermería en la unidad de cuidado intensivo (UCI), y causa un deterioro funcional, así como la inestabilidad en la salud de estos profesionales. Objetivo: Describir, a través de una revisión integradora, el estrés en el trabajo de enfermería en la UCI e identificar los factores, los signos y los sintomas asociados con el estrés en el trabajo. Método: Se trata de una revisión integrativa que utiliza información tomada de la Biblioteca Virtual en Salud (BVS), publicada entre 2002 y 2012. Resultados: La información analizada permitió caracterizar los principales hallazgos en tres categorias: 1) prevalencia de estrés experimentado por el personal de enfermería en la UCI; 2) factores que causan estrés en la UCI y sus consecuencias para el profesional enfermero, y 3) signos y sintomas de estrés en el profesional de enfermería en el ambiente de la UCI. Los resultados demostraron la magnitud y los principales agravantes de este trastorno en los profesionales. Conclusión: El estrés laboral puede afectar a todos y cada uno de los trabajadores, pues todo trabajo está sujeto a características específicas que pueden causar situaciones estresantes. Es necesario identificar qué medidas y qué técnicas pueden minimizar los efectos del estrés para los profesionales que trabajan en la UCI, a fin de garantizar su bienestar, en pro de ejecutar un trabajo de calidad.

Palabras clave: estrés ocupacional; enfermería; unidad de cuidados intensivos 


\section{Introdução}

O trabalho surgiu juntamente com o primeiro ser humano, mas as relações entre as atividades laborais e as doenças desencadeadas pelo trabalho, permaneceram praticamente ignoradas até 250 anos atrás (1). O trabalho e o local onde se desenvolve, por muitas vezes são condições propulsoras para o adoecimento de muitos trabalhadores. Essa problemática tem sido o alvo de muitos pesquisadores com o intuito de desenvolverem ações voltadas para a redução ou proporem meios para reduzirem os efeitos negativos dessas atividades e ambientes para o ser humano, na medida em que o trabalho deixou de ser um meio para realização pessoal e profissional, e passou a ser um causador e desenvolvedor de estresse (2).

O estresse é um mal que atinge a população em geral, formado por diversos fatores e constituindo uma síndrome que está associada às condições da vida moderna, ao sedentarismo, a sobrecarga de trabalho e ao estilo de vida. É um distúrbio que tem crescido de forma alarmante entre as pessoas de todo o mundo e afetado principalmente os trabalhadores da área da saúde, em especial, a equipe de enfermagem $(3,4)$.

Essa patologia pode ser definida, também, como uma reação do organismo através de componentes físicos e/ou psicológicos, causada pelas alterações psicofisiológicas ocorridas quando o ser é confrontado com uma situação irritante, amedrontante, entristecedor, excite ou confunda $(6,7)$ ou compreendido como uma relação isolada entre uma pessoa, seu ambiente e as circunstâncias com as quais está sendo submetido, sendo entendida pela pessoa como uma ameaça ou algo que exige dela além das suas próprias habilidades ou recursos dos quais o coloquem em risco $(8,9)$.

O trabalho, sendo uma atividade que requer do ser humano uma relação de bem-estar física e psíquica, no ambiente hospitalar está relacionada intrinsecamente com o equilíbrio entre o desenvolvimento e a satisfação da realização das funções, mas quando isso não ocorre, gera uma serie de complicações, tensões, desajustes e consequentemente o desequilíbrio e o adoecimento do trabalhador. Essas alterações acabam provocando um desgaste físico e metal que vão influenciar significativamente para o surgimento de transtornos ligados ao estresse como, a depressão, ansiedade, transtorno do pânico, fobias, padrões de sono irregular e doenças psicogênicas, o que consequentemente pode ter queda da produtividade, insatisfação, ineficiência e desorganização do trabalho (8-12).

O ambiente hospitalar gera estresse de várias naturezas e em vários níveis: o estresse do paciente e de seus familiares, o estresse dos profissionais e do pessoal de saúde envolvidos, a morte, a constatação de que nem sempre os pacientes fazem o que lhes é recomendado, colocando em risco ou anulando os mais delicados esforços, a sobrecarga ou trabalhos realizados em contextos que, muitas vezes, não permitem um final feliz ou, então, pressupõem requisitos desagradáveis e dolorosos para os pacientes $(13,14)$.

Os profissionais da saúde parecem sofrer tensões específicas de estresse ocupacional. De acordo com Zacabi (15), ela ocupa o terceiro lugar das profissões mais estressantes. Acredita-se que eles enfrentem altos niveis 
de estresse no trabalho, que se elevam em unidades de terapia intensiva $(16,17)$. Profissionais que trabalham neste setor podem desenvolver diversas patologias $(16,18)$.

Geralmente o estresse ocupacional caracteriza-se pela tensão emocional crônica gerada pelo contato diário, excessivo e estressante com o campo de trabalho, provocando sinais e sintomas de despersonalização, insatisfação com o trabalho e exaustão emocional, afetando de forma negativa e drasticamente a sua eficiência, habilidade e organização para a realização de suas funções no ambiente profissional $(3,19)$, o que vai causar perda de interesse nos fatores que estão ligados a sua vida profissional e pessoal $(20,21)$.

Reações a essas situações estressantes ao trabalho podem ser avaliadas pelo balanço entre esforço e recompensa (22). O equilíbrio entre esforço e recompensa se dá quando o trabalhador sabe lidar ativa ou passivamente no enfrentamento de problemas. O modelo utilizado para avaliar situações estressantes mostra que situações em que não há reciprocidade entre esforço e recompensa provoca reações negativas nos aspectos emocionais e fisiológicos no trabalhador (23).

No que tange a Enfermagem, vários são os autores que a classifica como uma profissão estressante, devido a sua realidade profissional está ligada diretamente e de forma interrupta com a dor, morte, sofrimento, desespero, incompreensão, irritabilidade, sobrecarga de trabalho para poder ter uma estabilidade financeira, falta de medicamentos e equipamentos no setor em que trabalha e outros sentimentos e reações originadas do processo doença, que acabam refletindo no profissional e o problema tende a se manifestar de forma mais evidente $(2,24,25)$.

O enfermeiro possui uma vasta atuação em diversos setores da saúde (26), os quais muitas vezes requerem do profissional um esforço maior, exigindo um bom preparo técnico e teórico para prestar com competência e responsabilidade as suas devidas funções, o que acaba gerando uma pressão física, psicológica e desgaste sobre o mesmo (27).

A unidade de terapia intensiva (UTI) seria um dos ambientes mais agressivos e desgastantes para o profissional, por se tratar da ala em que se encontra o menor número de leitos, porém internados os pacientes que necessitam de maior assistência e atenção redobrada. A complexidade desse serviço provoca alto nível de ansiedade e tensão, sobretudo pela elevada responsabilidade que a enfermagem exerce em seu cotidiano, colocando em risco a sua qualidade de vida (28-32).

Para o enfermeiro que atua nesse setor é necessário ter habilidade e perfil de líder, que saiba transmitir conhecimentos e que tenha controle emocional sobre as situações as quais será exposto. Devido ser um ambiente estressante, provoca um processo de desgaste físico e emocional muito grande entre os profissionais desse segmento (33-35).

Sabe-se que a equipe de enfermagem presta com inteira satisfação a assistência aos pacientes críticos, entretanto vivenciam situações angustiantes intensas pelo grande numero de procedimentos a serem realizados $(36,37)$. Ademais, a equipe tem que lidar no seu dia a dia com a manipulação 
de diversos equipamentos, ritmo intenso do trabalho e com a possibilidade de agravos e morte de pacientes. Cabendo ainda, realizar todas as atividades com iniciativa, rapidez e de forma minuciosa para não haver erros que possam gerar a morte de algum cliente (28).

O estresse ocupacional tem sido um tema bastante abordado entre as pesquisas e vem demonstrado a cada dia ser uma das patologias que mais acometem os profissionais da área saúde, devido estar em contato diariamente com situações que provocam desgaste físico e mental. Sendo a Enfermagem a classe profissional que mais está em contato com essas situações (38), acredito que a realização desse estudo, possa contribuir para a identificação dos principais agravos e fatores que vem interferindo no trabalho da equipe de enfermagem nas UTI bem como, subsidiar fontes literárias para pesquisas na área que vão ajudar na construção e no entendimento de medidas de prevenção para esses agravos.

Considerando tais reflexões, esse estudo tem como objetivos: descrever, através da revisão de literatura, o estresse no trabalho da equipe de enfermagem na UTI; identificar os fatores associados ao estresse ocupacional e os principais sinais e sintomas relacionados ao estresse.

\section{Metódo}

Trata-se de uma pesquisa de natureza bibliográfica, do tipo narrativa, que objetiva o pesquisador a investigação e a busca de conhecimentos existentes na literatura com base em material já elaborado, formado principalmente de livros e artigos científicos, ou seja, trabalhos científicos publicados. Essa pesquisa, ainda, traz a vantagem de proporcionar uma vasta e ampla cobertura de uma gama de fenômenos, mais do que um estudo pesquisado de forma direta (39).

Esse tipo de estudo é formado por fontes secundárias, pois os dados que o constituem são levantados de fontes que contém diferentes propósitos e informações, mas que tratam de um determinado e específico problema em estudo, sendo obtidos muitas vezes de maneira mais rápida, podendo ser extraídos de livros, revistas e sites, tendo como objetivo principal adquirir informações relevantes (40).

A construção de uma pesquisa bibliográfica é feita por etapas que se estruturam desde a escolha do tema a ser estudado, passando pela identificação e localização das fontes na língua portuguesa até a elaboração do problema e organização sistêmica do plano que forma o objeto de estudo. As fontes utilizadas para formulação desse estudo foram encontradas por meio da busca eletrônica no banco de dados da Biblioteca Virtual de Saúde (BVS), utilizando como palavras chave as expressões: enfermagem, terapia intensiva e estresse.

Para os critérios de inclusão foram escolhidos os artigos procedentes de fontes primárias que abordassem fatores desencadeantes do estresse na equipe de enfermagem na UTI, periódicos na língua portuguesa, publicadas no período entre 2002 e 2012, por se tratar de um trabalho de conclusão de curso de pós-graduação. Tivemos como critérios de exclusão artigos oriundos 
de outras revisões da literatura, reflexões teóricas, relatos de caso, editorial, artigos em outros idiomas e, também, aqueles em que seus objetivos não se aproximavam do tema proposto ou aqueles que estariam fora do recorte temporal pré-estabelecido.

Após ter sido aplicado os critérios de inclusão e exclusão, foram selecionados 10 artigos. Posto isso, os dados foram analisados e agrupados na tabela 1, caracterizando e nomeando três categorias para posterior discussão das informações encontradas.

\section{Resultados e discussão}

Para a realização da análise e discussão dos dados identificados após a leitura dos artigos, levou-se em consideração o autor da pesquisa, o ano de publicação, o periódico, a metodologia e o local de estudo. A partir dessas variáveis foi possivel descrever os seguintes resultados, vistos na tabela 1 .

TABela 1. Caracterização do estudo por autor, ano, periódico, tipos de sujeito, local de estudo e metodologia

\begin{tabular}{|c|c|c|c|c|}
\hline Autor/ano & Periódico & $\begin{array}{c}\text { Sujeitos da } \\
\text { pesquisa }\end{array}$ & $\begin{array}{c}\text { Local de } \\
\text { estudo }\end{array}$ & Metodologia \\
\hline $\begin{array}{l}\text { Santos et al., } 2010 \\
\text { (41) }\end{array}$ & $\begin{array}{l}\text { Rev. Eletrônica } \\
\text { Saúde Mental } \\
\text { Álcool e Drogas }\end{array}$ & - & - & $\begin{array}{l}\text { Estudo } \\
\text { bibliográfico }\end{array}$ \\
\hline $\begin{array}{l}\text { Coronetti et al., } \\
2011 \text { (42) }\end{array}$ & $\begin{array}{l}\text { Arquivos } \\
\text { Catarinenses } \\
\text { de Medicina }\end{array}$ & $\begin{array}{l}6 \text { enfer- } \\
\text { meiros; } 8 \\
\text { técnicos de } \\
\text { enfermagem, } \\
\text { e } 7 \text { auxilia- } \\
\text { res de enfer- } \\
\text { magem }\end{array}$ & $\begin{array}{l}\text { Floria- } \\
\text { nópolis- } \\
\text { Santa } \\
\text { Catarina }\end{array}$ & $\begin{array}{l}\text { Estudo } \\
\text { qualitativo; } \\
\text { descritivo }\end{array}$ \\
\hline $\begin{array}{l}\text { Preto e Pedrao, } \\
2009 \text { (43) }\end{array}$ & $\begin{array}{l}\text { Revista Escola de } \\
\text { Enfermagem USP }\end{array}$ & $\begin{array}{l}21 \\
\text { enfermeiros }\end{array}$ & \begin{tabular}{|l} 
São \\
Paulo
\end{tabular} & $\begin{array}{l}\text { Estudo } \\
\text { quantitativo }\end{array}$ \\
\hline $\begin{array}{l}\text { Guerrer e Bianchi, } \\
2008 \text { (44) }\end{array}$ & $\begin{array}{l}\text { Revista Escola de } \\
\text { Enfermagem USP }\end{array}$ & $\begin{array}{l}263 \\
\text { enfermeiros }\end{array}$ & $\begin{array}{l}24 \text { capi- } \\
\text { tais bra- } \\
\text { sileiras }\end{array}$ & $\begin{array}{l}\text { Estudo } \\
\text { quantitativo }\end{array}$ \\
\hline $\begin{array}{l}\text { Silva et al., 2012) } \\
(45)\end{array}$ & $\begin{array}{l}\text { Revista de } \\
\text { Ciências da Saúde }\end{array}$ & $\begin{array}{l}20 \\
\text { enfermeiros }\end{array}$ & $\begin{array}{l}\text { Minas } \\
\text { Gerais }\end{array}$ & $\begin{array}{l}\text { Estudo } \\
\text { quantitativo; } \\
\text { transversal- } \\
\text { descritivo }\end{array}$ \\
\hline $\begin{array}{l}\text { Anjos et al., } 2008 \\
(46)\end{array}$ & $\begin{array}{l}\text { Revista Instituto } \\
\text { Ciências da Saúde }\end{array}$ & $\begin{array}{l}18 \\
\text { enfermeiros }\end{array}$ & $\begin{array}{l}\text { Campi- } \\
\text { nas-São } \\
\text { Paulo }\end{array}$ & $\begin{array}{l}\text { Estudo } \\
\text { quantitativo; } \\
\text { exploratório- } \\
\text { descritivo } \\
\end{array}$ \\
\hline $\begin{array}{l}\text { Lucas e Passos, } \\
2009 \text { (16) }\end{array}$ & $\begin{array}{l}\text { Revista de } \\
\text { Pesquisa: Cuidado } \\
\text { é Fundamental } \\
\text { Online }\end{array}$ & $\begin{array}{l}6 \text { enfer- } \\
\text { meiros; } 13 \\
\text { técnicos de } \\
\text { enfermagem; } \\
3 \text { auxiliares } \\
\text { de enferma- } \\
\text { gem }\end{array}$ & $\begin{array}{l}\text { Rio de } \\
\text { Janeiro- } \\
\text { Rio de } \\
\text { Janeiro }\end{array}$ & $\begin{array}{l}\text { Estudo } \\
\text { descritivo com } \\
\text { abordagem } \\
\text { qualitativa }\end{array}$ \\
\hline
\end{tabular}




\begin{tabular}{|l|l|l|l|l|}
\hline $\begin{array}{l}\text { Miranda e Stancato, } \\
2008 \text { (48) }\end{array}$ & $\begin{array}{l}\text { Revista Brasileira } \\
\text { de Terapia } \\
\text { Intensiva (RBTI) }\end{array}$ & - & - & $\begin{array}{l}\text { Estudo } \\
\text { bibliográfico }\end{array}$ \\
\hline $\begin{array}{l}\text { Cavalheiro et al., } \\
2008 \text { (49) }\end{array}$ & $\begin{array}{l}\text { Revista Latino- } \\
\text { Americana de } \\
\text { Enfermagem }\end{array}$ & $\begin{array}{l}75 \text { enfermei- } \\
\text { ros }\end{array}$ & $\begin{array}{l}\text { São Pau- } \\
\text { lo-São } \\
\text { Paulo }\end{array}$ & $\begin{array}{l}\text { Estudo } \\
\text { transversal }\end{array}$ \\
\hline $\begin{array}{l}\text { Lopes et al., } 2010 \\
(50)\end{array}$ & $\begin{array}{l}\text { Revista } \\
\text { Enciclopédia } \\
\text { Bioesfera }\end{array}$ & $\begin{array}{l}5 \\
\text { enfermeiros } \\
\text { e 15 } \\
\text { técnicos de } \\
\text { enfermagem }\end{array}$ & $\begin{array}{l}\text { Teresina- } \\
\text { Piauí }\end{array}$ & $\begin{array}{l}\text { Estudo de } \\
\text { caráter } \\
\text { exploratório } \\
\text { descritivo } \\
\text { de natureza } \\
\text { quantitativa }\end{array}$ \\
\hline
\end{tabular}

Fonte: Biblioteca Virtual de Saúde.

Após o levantamento bibliográfico e análise, evidenciamos os principais fatores e situações responsáveis por desencadear o estresse na enfermagem, bem como verificamos os niveis de incidência e prevalência dessa patologia no ambiente da UTI possibilitando assim, caracterizar esses achados em três categorias: 1) prevalência do estresse vivenciado pela enfermagem na UTI; 2) fatores causadores de estresse na UTI e suas consequências para enfermagem; e 3) principais sinais e sintomas de estresse na enfermagem no ambiente da UTI.

A pesquisa foi formada por uma amostra de 10 artigos, composta por diferenciados números de periódicos, todos abordando em seu contexto aspectos referentes ao estresse da enfermagem no ambiente da UTI. Entre os tipos de pesquisa prevaleceu à pesquisa quantitativa e o maior número de publicações ocorreu durante o ano de 2008.

\section{Prevalência do estresse vivenciado pela enfermagem na UTI}

O estresse gerado dentro do ambiente da UTI tem atingido em grande número os enfermeiros intensivistas. Em um estudo realizado com 263 profissionais atuantes em UTI em 81 hospitais das capitais brasileiras, onde se utilizou a escala de Bianchi de Stress, revelou que $60 \%$ dos enfermeiros pesquisados, levando em consideração que foram analisados individualmente, prevaleceu entre esses profissionais os níveis médios e de alerta para o estresse (41).

Assim como pacientes e familiares, a UTI é visto pelos próprios profissionais que nela atua, como um ambiente agressivo, cheio de tensões e traumas. Esse fato pode ser confirmado na pesquisa realizada com 1800 enfermeiros, onde $93 \%$ destes, afirmaram sentirem-se estressados pelo trabalho desenvolvido nesse ambiente (42).

Nessa perspectiva, Preto e Pedrão (45) chamam a atenção em seu estudo realizado em 5 hospitais filantrópicos do interior de São Paulo, utilizando o Inventário de Estresse em Enfermeiros, com 21 participantes, sendo 90,5\% do sexo feminino, revelou que $57,1 \%$ dos sujeitos, avaliam a sua unidade como fonte geradora de estresse e que 33,3\% acham a unidade estressante 
só em certas situações. Mas o que foi identificado na maioria dessas UTI é que são formadas por profissionais com idade entre 24 a 40 anos correspondendo a $90,4 \%$ e 9,6\% se constituem de enfermeiros com idade maior de 40 anos, revelando que o estresse nessas unidades pode estar ligado a pouca experiência que muitos desses profissionais ainda não possuem e que por isso muitos deles se submetem a se envolverem com áreas mais complexas, talvez na busca por experiência. Constatando que quanto maior a idade e o tempo de atuação nessas unidades, ganhando mais conhecimentos e experiências, o nível de estresse é menor entre os enfermeiros.

De maneira semelhante, uma pesquisa realizada em uma UTI no sul de Minas Gerais, constituída por 20 enfermeiros com idade entre 20 a 59 anos, sendo a faixa etária prevalente de 20 a 30 anos (50\%), com predominância significativa do sexo feminino (60\%), ao comparar a frequência de estresse levando em consideração a idade, observou-se que a faixa etária de 20 a 30 foi a que apresentou um índice de estresse mais elevado, quando equiparada com outras faixas etárias pesquisadas. Notou-se que a porcentagem de sintomas de estresse diminui nos grupos, com o avançar da idade (45).

Por outro lado, Guerrer e Bianchi (50) quando compararam o tempo de formado com os domínios da pratica do ambiente da UTI, observaram que os enfermeiros com menos de um ano e de dois a cinco anos de formados não apresentaram níveis mais elevados de estresse para nenhum domínio. Ao contrário dos enfermeiros entrevistados que ao se verificar a média total para cada faixa de tempo de formado, os enfermeiros com 11 a 15 anos e que tinham maiores domínios do ambiente e dentre experiências maiores, revelaram possuírem niveis mais elevados de estresse, com média de 3,79, ao contrário do esperado, que quanto maior o tempo de formado, menor o estresse, que seria explicado pelo fato do enfermeiro apresentar maior segurança técnica e controle sobre as situações que surgem em UTI, de tal forma que estas não se configurariam como estressantes.

Da mesma forma evidenciaram-se em outro estudo que os profissionais com maior tempo de trabalho na UTI (de 2 a 13 anos), foram os que mais apresentaram sintomas de estresse, seja na fase alerta, resistência ou exaustão, enquanto os profissionais de enfermagem mais novos no serviço (menos de 2 anos) não apresentaram qualquer sintoma de estresse, quando avaliados pelo Inventário de Sintomas de Stress para Adultos de Lipp (45).

Em um estudo realizado em uma UTI de um hospital privado na cidade de Teresina-Pi, com 14 profissionais atuantes nessa unidade, dentre os quais eram 04 Enfermeiros e 10 Técnicos de enfermagem, com predominância de idade entre 33 a 46 anos, perfazendo um total de $57,14 \%$, seguidos de 21 a 33 anos (42,9\%), sendo $71 \%$ destes do sexo feminino, revelou que $70 \%$ dos técnicos e $75 \%$ desses enfermeiros, apresentaram niveis de estresse referentes à sua ocupação profissional (50).

Já no levantamento realizado com 18 enfermeiros de uma UTIN, em uma maternidade em Campinas, São Paulo, ao serem questionados sobre questões pertinentes nesse ambiente do tipo: convencer os membros da chefia, incompatibilidade com superior hierárquico, incompetência de superior 
hierárquico, sentir-se desvalorizado, falta de funcionários e acúmulo de funções, $50 \%$ desses profissionais responderam ao um nivel máximo de estresse e quando avaliados pelo questionário sobre a prevalência do estresse para alguns fatores desencadeantes, 10,08\% responderam ausência de estresse para os fatores desencadeantes, $14,21 \%$ pouco estresse, $19,77 \%$ estresse moderado, enquanto que $23,64 \%$ apontaram nivel muito alto e $28,29 \%$ nível máximo (46).

A enfermagem é considerada por muitos autores como uma das profissões mais estressantes que existe uma vez que, no seu trabalho diário é obrigado a conviver com pessoas que sofrem e requerem atenções maiores, compaixão e simpatia. O profissional quando tem que lidar com essa situação, pode se sentir irritado, deprimido e desapontado, pois há convergências desses sentimentos com o desempenho da profissão, acarretando consequentemente culpa e aumento da ansiedade (43).

\section{Fatores causadores de estresse na UTI e suas consequências para enfermagem}

Em uma pesquisa realizada por Lucas e Passos (47), em uma UTI de um hospital público situado no município do Rio de Janeiro, sendo entrevistados 22 profissionais da equipe de enfermagem, entre técnicos de enfermagem e enfermeiros, constatou alguns fatores desencadeantes do estresse ocupacional no ambiente da UTI, dos quais tiveram destaque, as condições e a organização do trabalho, a falta de compreensão da família com o trabalho da equipe de enfermagem e o não reconhecimento familiar e a impotência diante as limitações do tratamento por não poderem fazer algo a mais pelo paciente, são representados por esses profissionais como causadores de insatisfação, frustrações e estresse.

Muitos são os fatores desencadeantes do estresse nos profissionais e que geralmente os leva a um excessivo consumo de café, álcool e tabaco. Em se tratando da enfermagem, existem no trabalho dos enfermeiros intensivistas, inúmeras fontes geradoras de estresse, entre as quais se incluem as condições ambientais, socioeconômico, cultural, organizacional e a própria assistência de enfermagem (46).

Por outro lado, Guerrer e Biachi (50) estabelecem em seu estudo a relação do estresse na enfermagem quanto ao cargo e domínio que alguns desses profissionais ocupam no ambiente de trabalho, como apontam nos casos dos enfermeiros chefes que apresentaram niveis mais elevados em dominios com atividades administrativas, assim como os enfermeiros assistenciais apresentaram índices mais elevados de estresse para domínios mais relacionados à assistência do paciente. Demonstrando assim, que o estresse também se encontra ligada ao tipo de cargo e atividades que o mesmo requer do profissional.

Entretanto, em uma pesquisa realizada por Preto e Pedrão (45), descrevem que profissionais iniciantes na carreira e que desenvolvem suas atividades em uma unidade de assistência extremamente complexa, a princípio 
poderão não desenvolver ou ter essa situação como fator de estresse, mas se futuramente esses profissionais não buscarem o aprimoramento e alternativas que facilitem o alivio das tensões provocadas pelo ambiente exaustivo e tenso e pelo árduo trabalho, é de supor que esses profissionais poderão desenvolver quadros patológicos, entre eles o estresse, que consequentemente irá interferir na qualidade de vida destes.

Preto e Pedrão (45) ainda chamam atenção para relação de outros aspectos que poderão desencadear o estresse na enfermagem. Perceberam em seu levantamento, que alguns enfermeiros que não possuíam especialização na área e que tinham mais de um emprego, apresentaram índices elevados perceptivos para estresse, confirmando assim, que a qualificação, a situação econômica e o ambiente de trabalho, formam-se em fatores que influenciam fortemente no desenvolvimento de quadros de estresse.

Já em um estudo realizado com base em relatos da equipe de enfermagem de duas UTI em Florianópolis, SC, revela diversos fatores estressantes como o ambiente físico, excesso de trabalho, o próprio relacionamento entre os profissionais e a rapidez na ação da assistência são indicados como os principais fatores que consequentemente causam o estresse na equipe de enfermagem, refletindo basicamente no relacionamento humano e que resulta em irritabilidade, intrigas, ansiedade, desmotivação e baixa produtividade desses profissionais (42).

Em consonância com isso, outra pesquisa mostra que fatores como, sobrecarga de trabalho, conflitos de funções, desvalorização, dupla jornada, falta de autonomia, insatisfação com o trabalho, relacionamento interpessoal, remuneração, ruído, acidentes biológicos e morte, são identificados pela enfermagem em seu trabalho em UTI como predisponentes ao estresse e que geram diversas perturbações na qualidade de vida profissional e pessoal, revelando que esse desgaste causado pelo estresse poderá levar o indivíduo ao estado de estresse (41).

Assim Miranda e Stancato (48), em seu levantamento bibliográfico acerca dos riscos á saúde da equipe de enfermagem que atua na UTI, descrevem que o estresse e outras consequências biopsicofisiológicas às quais os profissionais de uma UTI estão expostos, de forma cumulativa e progressiva, são desencadeados por fatores como ambiente de trabalho, sobrecarga de trabalho, relações interpessoais, trabalho noturno, tempo de serviço (intrínsecos) e condições pessoais e características da personalidade (extrínsecos), conforme estudo que levou em conta o problema entre enfermeiros brasileiros de 1982 a 2001. Outros agentes estressores apontados foram à organização do trabalho, sobretudo em ambiente com precariedade das condições laborais, o ambiente ruidoso, as relações conflitantes e as exigências impostas pelo trabalho.

O estresse desses profissionais é formado por um conjunto de fatores e situações dos quais se deparam diariamente no ambiente de trabalho. A insatisfação com o trabalho, somada a situações consideradas críticas pelos profissionais como, o conflito no relacionamento entre os profissionais, a falta de pessoal e material, o ritmo, tempo de trabalho e ruído constante das 
aparelhagens, podem levar ao quadro de estresse com surgimento de sintomas relacionados ao desencadeamento de fatores orgânicos que, se não controlados, predispõem a doenças graves e descontentamento com a profissão $(49,50)$.

\section{Principais sinais e sintomas do estresse nos profissionais de enfermagem atuantes no ambiente da UTI}

O estresse ocupacional pode se manifestar de várias maneiras, tanto de forma física quanto emocional. Dentre essas manifestações destacam-se, a presença de mãos frias, enxaqueca, perda do senso de humor, problemas de memória, pesadelos, insônia, irritabilidade excessiva, relatados pelos profissionais de Enfermagem atuantes no ambiente da UTI, prevalecendo com maior frequência os sintomas psicológicos que acabam interferindo no relacionamento e causando insatisfação no trabalho e consequentemente prejudicando a assistência prestada (42).

Em concordância com isso, os estudos realizados por Lucas e Passos (47), revelam que o estresse se manifesta através de sintomatologias físicas do tipo: cansaço constante, irritabilidade excessiva, diminuição da libido, mudança no apetite, hipertensão arterial, mau humor, insônia, dor lombar e cervical, pensar constantemente em um só assunto e sensação de desgaste físico, estado de exaustão, diarreia frequente, náuseas, tontura frequente. E sinais e sintomas emocionais e psicológicas quais sejam: angústia, ansiedade diária, vontade de fugir de tudo, que acabam repercutindo de forma negativa no ambiente de trabalho e na vida pessoal desses indivíduos, interferindo no relacionamento familiar e gerando até mesmo doenças como a depressão (50).

Nesse sentido, pesquisas caracterizam diversos sinais e sintomas secundários ao estresse nesses profissionais, que podem ocorrer de forma individual, única ou várias simultaneamente, sendo a taquicardia e o suor frio os mais relatados por eles, correspondendo a $41,2 \%$ dos dados encontrados e a hipertensão e arritmia a 35,3\%. Dentre outros constataram: aumento da sudorese, tensão muscular, taquicardia, hipertensão arterial, aperto da mandibula, ranger de dentes, hiperatividade, náuseas, mãos e pés frios na tentativa de adequação ao ambiente de trabalho (41).

Já outros autores Cavalheiro, Moura-Júnior e Lopes (49) avaliaram o estresse, descreveram e dividiram os sinais e sintomas na enfermagem de acordo com as alterações presentes nos sistema cardiovascular, aparelho digestivo e músculo-esquelético. Levando em consideração essas mesmas variáveis, foi possivel obter em outro estudo resultados significativos para a patologia, quando referidos pelos profissionais modificações quanto: a necessidade excessiva de dormir, gastrite, pirose, dores musculares na nuca cervical ou lombar, falta de apetite e cefaleia (46).

A identificação dos sinais e sintomas físicos e psicológicos sugestivos para o estresse ocupacional, na enfermagem, pode estar relacionada com a sua própria percepção da situação no ambiente laboral, já que é um trabalho 
que permite o contato direto com pessoas sendo assim, considerado agente estressor de grande magnitude, devido aos problemas e riscos que surgem (45).

\section{Conclusão}

Todo e qualquer trabalho, em sua particularidade, acaba se tornando estressante, seja devido o ambiente impróprio para sua atuação ou pela necessidade do profissional em se adequar as situações e imprevistos que ocorre durante a atividade laboral.

O estresse ocupacional é, sem dúvida, um dos males que tem afetado o profissional da enfermagem no seu ambiente de trabalho. As próprias funções da profissão e as responsabilidades designadas a esses profissionais requerem um esforço e dedicação muito grande e ao somarem com as situações, por muitas vezes dificultosas, da UTI, gera diversas perturbações e alterações físicas, emocionais e psicológicas nesses indivíduos, prejudicando a qualidade da assistência oferecida nesse local.

Levantamos nessa pesquisa os principais dados pertinentes para o estudo dessa patologia na UTI, revelando sua prevalência, os fatores desencadeantes e os sinais e sintomas que a sugerem. Demonstrando que apesar da sua notória presença nesse setor da saúde e causando diversos transtornos para a enfermagem e para o ambiente no total, não constatamos medidas e técnicas que poderiam ser utilizadas para diminuir e minimizar os efeitos do estresse para esses profissionais, fator limitante no referido estudo.

Visto o exposto acerca da temática estudada, observou-se uma carência sobre tema pouco estudado, sendo necessário a elaboração de mais estudos de intervenção clínica que analisem métodos e estratégias eficazes na profilaxia nos fatores desencadeadores desse agravo aos profissionais de enfermagem nas UTI.

\section{Conflito de interesses}

Os autores declaram não haver conflito de interesses.

\section{Financiamento}

Nenhum.

\section{Referências}

1. Haag GS, Lopes MJM, Schuck JS. A Enfermagem e a saúde dos trabalhadores. 2a ed. Goiânia: AB; 2001.

2. Harbs TC, Rodrigues ST, Quadros VAS. Estresse da equipe de enfermagem de um centro de urgência e emergência. Paraná: Boletim de Enfermagem [internet]. 2008;1(2). Disponivel em: http://www.utp.br/ enfermagem

3. Almeida F, Munhoz CJM. Enfermeiros e sua equipe ligada por sua relação com o estresse. Revista Florence [internet]. 2011 maio [citado 15 de abril 2013];1(1):54-62. Disponivel em: http://www.florence.edu.br

4. Santos FE, Alves JÁ, Rodrigues AB. Síndrome de burnout em enfermeiros atuantes em uma unidade de terapia intensiva. Rev Einstein. 
2009;7(1):58-63. Disponivel em: http://apps.einstein.br/revista/arquivos/PDF/979-Einsteinv7n1p58-63.pdf

5. Coleman V. Técnicas de controle de estresse: como administrar a saúde das pessoas para aumentar os lucros. Rio de Janeiro: Imago; 1992.

6. Malagris LEN, Fiorito ACC. Avaliação do nível de stress de técnicos da área de saúde. Estudos de Psicologia (Campinas). 2006;23(4):391-8. Disponivel em: http://www.scielo.br/scielo. php?pid=S0103-166X2006000400007\&script=sci_abstract\&tlng=pt

7. Lipp MEM. O stress está dentro de você. São Paulo: Contexto; 1999.

8. Paiva GS. Monteiro ARM. Manifestações de estresse em enfermeiros de unidade de terapia intensiva. Rev RENE [internet]. 2004 jul-dez [citado 15 maio 2013];5(2):9-16. Disponivel em: http://www.revistarene.ufc.br/revista/index.php/revista/article/view/917

9. Belancieri MF. Enfermagem: estresse psicossomático. Bauru: EDUSC; 2005.

10. Perruzo GS. O stress ocupacional da equipe de enfermagem atuante em UTI neonatal [monografia]. Criciúma: Universidade do Extremo Sul Catarinense; 2011 [citado 15 maio 2013]. Disponível em: http:// www.bib.unesc.net/biblioteca/sumario/00004F/00004F31.pdf

11. Camelo SHH, Angerami ELS. Riscos psicossociais no trabalho que podem levar ao estresse: uma análise da literatura. Cienc Cuid Saúde. 2008;7(2):232-40. Disponivel em: http://www.periodicos.uem.br/ojs/ index.php/CiencCuidSaude/article/view/5010/3246

12. Battison T. Vença o estresse: o homem moderno. São Paulo: Manole; 1998. p. 80.

13. Miquelim JDL, Carvalho CBO, Gir E, Pelá NTR. Estresse nos profissionais de enfermagem que atuam em uma unidade de pacientes portadores de HIV-AIDS. DST-J Bras Doenças Sex Transm [internet]. 2004 [citado 15 maio 2013];16(3):24-31. Disponivel em: http://bases.bireme.br/

14. StacciarinI JMR, Troccoli BT. O estresse na atividade ocupacional do enfermeiro. Rev Latino-AmEnferm. 2001;9(2):17-25. Disponivel em: http://www.scielo.br/scielo.php?script=sci_arttext\&pid=S010411692 $001000200003 \& \operatorname{lng}=$ pt\&nrm=i

15. ZakabI R. Stress: ninguém está a salvo desse mal moderno, mas é possivel aprender a viver com ele. Revista Veja. 2004;37(6):66-75.

16. Fields AL, Cuerdon TT, Brasseux CO, Getson PR, Thompson AE, Orlowski JP et al. Physician burnout in pediatric care medicine. Crit Care Med. 1995 Aug;23(8):1425-9. Disponivel em: http://www.ncbi. nlm.nih.gov/pubmed/7634815

17. Cronqvist A, Lützén K, Nyström M. Nurses' lived experiences of moral stress support in the intensive care context. J Nurs Manag. 2006 Oct;14:405-13. Disponível em: http://www.ncbi.nlm.nih.gov/ pubmed/16787476

18. Arriortua AB, Cid JL, Álvarez AC, Escribano V, García LN, Carvavilla EP. Situación de burnout de los pediatras intensivistas españoles. An Esp Pediatr. 2000 Mar;52:418-23. Disponivel em: http://www.bvsde. paho.org/bvsacd/cd49/pediatras.pdf 
19. Barboza JIRA, Moraes EL, Pereira EA, Reimão RNAA. Avaliação do padrão de sono dos profissionais de enfermagem dos plantões noturnos em unidades de terapia intensiva. Einstein. 2008.6(3):296301. Disponível em: http://www.scielo.br/scielo.php?script=sci_ nlinks\&ref=000111\&pid=S0104-1169201100050000800017\&lng=pt

20. Codo W, Vasques-Menezes I. O que é burnout? Em: Codo W, org. Educação: carinho e trabalho. Rio de Janeiro: Vozes; 1999. p. 237-55 Disponivel em: http://www.scielo.br/scielo.php?script=sci_ nlinks\&ref=000071\&pid=S1414-9893200200020000400007\&lng=en

21. Pafaro RC, De Martino MMF. Estudo do estresse do enfermeiro com dupla jornada de trabalho em um hospital de oncologia pediátrica de Campinas. Revescenferm USP. 2004;38(2):152-60. Disponivel em: http://www.scielo.br/scielo.php?script=sci_arttext\&pid=S008062342 004000200005\&lng=en\&nrm=iso

22. Siegrist J. The model of effort-reward imbalance: Theorical backgroud. Information and documentation-bibliographic references [internet]. 1999. Disponivel em: http://www.uni-duesseldorf.de/www/ workstress/htm

23. Fogaça MC, Carvalho WB, Cícero VA, Nogueira-Martins LA. Fatores que tornam estressante o trabalho de médicos e enfermeiros em terapia intensiva pediátrica e neonatal: estudo e revisão bibliográfica. Rev Latino-Am Enfermagem. 2010;18(1):[6 telas] [citado 15 de maio 2013]. Disponivel em: www.revistas.usp.br/rlae/article/viewFile/4121/5007

24. Versa GLGS, Murassaki ACY, Inoue KC, Augusto de Melo W, Faller JW, Matsuda LM. Estresse ocupacional: avaliação de enfermeiros intensivistas que atuam no período noturno. Rev Gaúcha Enferm. Porto Alegre (RS). 2012 jun;33(2):78-85. Disponivel em: http://www.scielo. $\mathrm{br} / \mathrm{pdf} / \mathrm{rgenf} / \mathrm{v33n} 2 / 12 . \mathrm{pdf}$

25. Grubits S, Guimarães LAM, orgs. Série saúde mental e trabalho. Vol. 1. São Paulo: Casa do Psicólogo; 2004.

26. Svaldi JSD, Siqueira HCH. Ambiente hospitalar saudável e sustentável na perspectiva ecossistêmica: contribuições da enfermagem. Esc Anna Nery. 2010 jul-set;14(3):599-604 Disponivel em: http://www.scielo.br/ pdf/ean/v14n3/v14n3a23.pdf

27. Holmes DS. Psicologia dos transtornos mentais. 2a ed. Porto Alegre: Artes Médicas; 1997.

28. Araújo AKF, Ferreira AS, Paone LD, Silva RP, Ventura MR. Estresse dos graduandos de enfermagem trabalhadores de uma unidade de terapia intensiva. ConScientia e Saúde [internet]. 2008 [citado 15 de abril 2013];7(3):391-6. Disponivel em: http://www.uninove.br

29. Hoga LAK. Causas de estresse e mecanismos de produção do bemestar dos profissionais de enfermagem de unidade neonatal. Acta Paul Enfermagem. 2002;15(2):18-25. Disponível em: http://www. scielo.br/scielo.php?script=sci_nlinks\&ref=000122\&pid=S01032100200600030000900008\&lng=pt 
30. Pereira MER, Bueno SMV. Lazer: um caminho para aliviar as tensões no ambiente de trabalho em UTI: uma concepção da equipe de enfermagem. Rev Latinoam Enfermagem. 1997;5(4):75-83. Disponivel em: http:// www.scielo.br/scielo.php?script=sci_nlinks\&ref=000128\&pid=S01032100200600030000900014\&lng=en

31. Araújo AD, Santos JO, Pereira LV. Trabalho no centro de terapia intensiva: perspectivas da equipe de enfermagem. REME. 2005;9(1):208. Disponível em: http://www.ibrati.org/sei/docs/tese_571.doc

32. Ritter RS, Stumm EMF, Kircher RM. Análise de burnout em profissionais de uma unidade de emergência de um hospital geral. Rev Eletr Enf. 2009;11(2):236-48. Disponivel em: http://www.fen.ufg.br/revista/v11/n2/v11n2a02.htm

33. Silva ABHC. O estresse na prática profissional do psicólogo em UTI: uma revisão de literatura. Rev SBPH [internet]. 2010 Jun;13(1):33-51. Disponível em: http://pepsic.bvsalud.org/scielo. php?script=sci_arttext\&pid=S1516-08582010000100004\&lng=pt

34. Gomes A M. Enfermagem na unidade de terapia intensiva. 2a ed. São Paulo: EDU; 1988. Disponivel em: http://www.scielo.br/scieloOrg/ php/reflinks.php?refpid=S0104-1169199900050000300007\&lng=en \&pid=S0104-11691999000500003

35. Hudak CM, Gallo BM. Cuidados intensivos de enfermagem: uma abordagem holística. Rio de Janeiro: Guanabara Koogan; 1997.

36. Ferrareze MVG, Ferreira V, Carvalho AMP. Percepção do estresse entre enfermeiros que atuam em Terapia Intensiva. Acta Paul Enferm [internet]. 2006;19(3):310-5. Disponivel em: http://dx.doi.org/10.1590/ S0103-21002006000300009.

37. Boog GG. O que o trabalho significa para cada um de nós. 2005. Disponivel em: http://carreiras.empregos.com.br/rh/colunistas/250402boogtrabalho.shtm

38. Shimizu HE, Ciampone MHT. Sofrimento e prazer no trabalho vivenciado pelas enfermeiras que trabalham em unidades de terapia intensiva em um hospital escola. Rev Esc Enfermagem USP. 1999;33(1):95-106. Disponivel em: http://www.scielo.br/scielo. php?pid=S0080-62341999000100010\&script=sci_arttext

39. Gil AC. Como elaborar projetos de pesquisa. 4a ed. São Paulo: Atlas; 2002.

40. Medeiros JB. Redação científica: a prática de fichamento, resumo, resenhas. 4ed. São Paulo: Atlas; 2000.

41. Santos FD, Cunha MHF, Robazzi MLCC, Pedrão LJ, Silva LA, Terra FS. O estresse do enfermeiro nas unidades de terapia intensiva adulto: uma revisão da literatura. SMAD. Rev Eletrônica Saúde Mental Álcool Drog [internet]. 2010 [citado 15 maio 2013];6(1):1-16. Disponível em: http://pepsic.bvsalud.org/scielo.php?script=sci_arttext\&pid=S18 0669762010000100014\&lng=pt\&nrm=iso

42. Coronetti A, Nascimento ERP, Barra DCC, Martins JJ. Estresse da equipe de enfermagem na unidade de terapia intensiva: O enfermeiro 
como mediador. Arquivos Catarinenses de Medicina [internet]. 2006 [citado 15 maio 2013];35(4):36-43. Disponivel em: http://bases.bireme.br/

43. Preto VA, Pedrao LJ. O estresse entre enfermeiros que atuam em unidade de terapia intensiva. Rev Esc Enferm USP [internet]. 2009 dez [citado 15 maio 2013];43(4):841-8. Disponivel em: http://www.scielo. br/scielo.php?script=sci_arttext\&pid=S008062342009000400015\& lng=en\&nrm=iso

44. Guerrer FJL, Bianchi ERF. Caracterização do estresse nos enfermeiros de unidades de terapia intensiva. Rev Esc Enferm USP [internet]. 2008 jun [citado 15 maio 2013];42(2):355-62. http://dx.doi.org/10.1590/ S0080-6234200800020002

45. Silva PCS, Filipini CB, Prado BO, Soares EA, Duarte GGM. Avaliação do nivel de estresse da equipe de enfermagem em terapia intensiva. Revista Ciências em Saúde [internet]. 2012 out [citado em 15 maio 2013];2(4):6-14. Disponivel em: http://200.216.240.50:8484/rcsfmit/ ojs-2.3.3-3/index.php/rcsfmit_zero/article/view/124

46. Anjos DR, Silva EA, Falqueiro HJA, Freitas PMP, Peres VPM, Massruhá VC, et al. Estresse-fatores desencadeantes, identificação e avaliação de sinais e sintomas no enfermeiro atuante em UTI neonatal. Rev Inst Ciênc Saúde [internet]. 2008 [citado 15 de abril 2013];26(4):426-31. Disponivel em: http://bases.bireme.br/

47. Lucas JS, Passos JPO. Estresse no trabalho da equipe de enfermagem em unidade de terapia intensiva. Rev Pesq: Cuidado é Fundamental [internet]. 2009 set-dez [citado 15 maio 2013];1(2):345-52. Disponível em: http://www.seer.unirio.br/index.php/cuidadofundamental/article/ viewArticle/411

48. Miranda EJP, Stancato K. Riscos à saúde de equipe de enfermagem em unidade de terapia intensiva: proposta de abordagem integral da saúde. Rev Bras Ter Intensiva [internet]. 2008 mar [citado 15 maio 2013];20(1):68-76. Disponível em: http://www.scielo.br/ scielo.php?script $=$ sci_arttext\&pid=S0103-507X2008000100011\&1n $\mathrm{g}=\mathrm{en} \& \mathrm{nrm}=$ iso

49. Cavalheiro AM, Moura-JúniorDF, Lopes AC. Estresse de enfermeiros com atuação em unidade de terapia intensiva. Rev Latino-Am Enfermagem [internet]. 2008 fev [citado 15 de maio 2013];16(1). Disponivel em: http://www.scielo.br/scielo.php?script=sci_arttext\&pid=S0104 11692008000100005\&lng=pt\&nrm=isso

50. Lopes RC, Silva JWF, Costa RM, Silva GB. O estresse ocupacional entre profissionais de enfermagem de uma unidade de terapia intensiva. Rev Enciclopédia Biosfera [internet]. 2010 [citado 17 maio 2013];6(9):1. Disponivel em: http://www.conhecer.org.br/enciclop/enciclop.htm 
